\title{
Threshold estimation with the P1-N1-P2 cortical auditory evoked potentials
}

\section{İşitsel uyarılmış P1-N1-P2 kortikal potansiyellerle eşik incelemesi}

\author{
Sıdıka CESUR ${ }^{\circ}$, Ufuk DERINSU $\mathbb{}$
}

\section{ABSTRACT}

Aim: The aim of the study was to compare the hearing threshold levels obtained by cortical auditory evoked responses and classic behavioral audiometry in adults with normal hearing and sensorineural hearing loss and to investigate the intercompatibility of these two tests.

Methods: In this study 74 adults consisting of 18 individuals with normal, and 56 impaired hearing were evaluated and threshold levels of ALRs obtained with both tests at 500, 1000, 2000 and 4000 $\mathrm{Hz}$ frequencies and behavioural thresholds were compared.

Results: In adults with normal hearing any correlation between AEPs and behavioral thresholds was not found at $500 \mathrm{~Hz}$, while moderate, and weak correlations were detected at 1000 and $2000 \mathrm{~Hz}$, also at $4000 \mathrm{~Hz}$, respectively. While in adults with hearing loss strong correlations were detected at all of the tested frequencies. The biggest mean difference between two tests values were $5 d B$ in normal and $7.4 d B$ in individuals with hearing disorders.

Conclusion: ALRs have showed good correlations in individuals with pure tone behavioral thresholds at 500,1000, and $4000 \mathrm{~Hz}$ frequencies in patients with normal hearing and those with hearing loss. Therefore it may be suggested ALRs may be recommended as a reliable and accurate test to estimate pure tone thresholds in adults and children uncooperative to behavioural thresholds, forensic cases and subjects with nonorganic hearing loss.

Keywords: Auditory Late Response (ALRs), threshold estimation, nonorganic, hearing öz

Amaç: Çalışmanın amacı, normal işitmeli ve sensörinöral işitme kayıplı yetişkinlerde işitsel uyarılmış geç potansiyeller (IUGP) ve klasik davranışsal tekniklerle elde edilen işitme eşiği sonuçlarını karşılaştırmak ve bu iki testin birbiri ile ne kadar uyumluluk gösterdiğini araştırmaktır.

Yöntem: Çalışmaya 18 normal işiten (33 kulak), 56 işitme kayıplı (112 kulak) olmak üzere toplam 74 yetişkin (145 kulak) alınmış ve 500, 1000, 2000 ve $4000 \mathrm{~Hz}$ frekanslarında elde edilen IUGP ve davranım eşikleri karşılaştırılmıştır.

Bulgular: Normal işitenlerde iUGP ve davranım eşikleri arasında $500 \mathrm{~Hz}$ 'de korelasyon olmadığı, 1000 ve 2000 Hz'de orta, 4000 $H z^{\prime} d e$ zayıf bir korelasyon olduğu, işitme kayıplılarda ise tüm frekanslarda yüksek derecede bir korelasyon olduğu görülmüştür. Her iki ölçüm ortalamaları arasındaki en büyük fark değeri normal işitenlerde $5 \mathrm{~dB}$, işitme kayıplılarda ise $7.4 \mathrm{~dB} \mathrm{~B}^{\prime}$ dir.

Sonuç: Sonuç olarak, iUGP'nin 500, 1000, 2000 ve $4000 \mathrm{~Hz}$ frekanslarında saf ses davranım eşikleri ile normal ve işitme kayıplı kişilerde yüksek oranda uyumluluk gösterdiği görülmüştür. Bu nedenle iUGP'yi, davranım eşiklerine kooperasyonu olmayan çocuk ve yetişkinlerde, adli vakalarda ve nonorganik işitme kayıplarında eşik yordamak üzere kullanılabilecek uygun ve güvenilir bir test olarak önermek olasıdır.

Anahtar kelimeler: iUGP (İşitsel uyarılmış geç potansiyeller), eşik belirlenmesi, non-organik, işitme

\section{Giriş}

Son zamanlarda işitme sağlığı ve güvenliğine verilen önemin artması ile işitmenin ölçüm ve değerlendirmesi de önem kazanmıştır. Klinikte işitmenin ölçül- mesinde yaygın olarak klasik davranışsal odyometrik testler kullanılmaktadır. Bu testler büyük ölçüde kişinin ve testi yapanın katılımını gerektiren subjektif testlerdir ${ }^{1}$. Ancak klasik odyometrik testlerin yapılmasının olası olmadığı yaştaki bebek ve küçük ço-

Received: 04.04 .2018

Accepted: 15.07 .2018

Marmara University, Department of Audiology, Istanbul, Turkey

Yazışma adresi: Sıdıka Cesur, Marmara University, Department of Audiology, Istanbul, Turkey

e-mail: sdkacesur@gmail.com

Yazarların ORCiD bilgileri:

S.C. 0000-0003-1479-6495, U.D. 0000-0003-0438-0074 
cuklarda, zekâ geriliği ve iletişim bozukluğu olanlarda, nörolojik rahatsızlıklarda, komadaki hastalarda, medikolegal vakalarda ve nonorganik işitme kayıpları gibi durumlarda işitmenin değerlendirilmesi için objektif testlere gerek duyulmaktadır. Bu amaçla yaygın olarak elektrofizyolojik testler kullanılmaktadır ${ }^{1,2}$. Elektrofizyolojik testler; beynin bir uyarıyı alması ya da bir uyarı ile motor cevap oluşturması sırasında ilgili kısımlarında oluşan biyoelektriksel potansiyellerin kaydedilmesine dayalı testlerdir ${ }^{3,4}$. Kullanılan uyarana ve potansiyellerin elde edilişlerine göre duyusal, motor ve olaya ilişkin olmak üzere pek çok elektrofizyolojik test bulunmaktadır. Duyusal uyarılmış potansiyeller görsel, işitsel veya elektriksel uyaranlar kullanılarak elde edilmektedir. İşitsel uyaran kullanılması ile elde edilen potansiyellere işitsel uyarılmış potansiyeller (IUP) denilmektedir. Kafa derisinin yüzeyine yerleştirilen elektrotlar aracılığıyla kaydedilen bu potansiyeller işitme siniri, beyin sapı ve korteksteki uyarının oluşturduğu voltaj değişikliklerini göstermektedir ${ }^{1,5}$.

Klinik ve teorik olarak işitsel uyarılmış potansiyeller gözden geçirildiğinde objektif eşik ölçümlerinde özellikle yetişkin bireylerde en optimize ve uygun test yöntemi olarak İşitsel Uyarılmış Geç Potansiyeller (iUGP)'in önerildiği görülmektedir ${ }^{6,7}$. Pek çok çalışmada nonorganik ve mesleki işitme kayıplı kişilerde işitme kaybını değerlendirmek üzere IUGP'nin yeğlendiği görülmektedir ${ }^{5,8,9}$. Benzer şekilde Boniver'in 2002 yılında yaptığı çalışmada, IUGP ile davranışsal odyometrik eşikler arasında anlamlı bir farklılık olmadığı ve iUGP'nin nonorganik işitme kayıplarında kullanılabilecek güvenilir bir test olduğu ileri sürülmüştür ${ }^{10}$.

Yavaş hızda verilen bir uyarana karşı yaklaşık 50-250 ms. arasında bir sürede meydana gelen bir dizi pozitif ve negatif tepeden oluşan IUGP'nin en temel bileşenlerini N1 dalgası ve P2 dalgası oluşturmaktadır (Figür 1). Talamus ve daha üst düzey işitme merkezinin aktivitesini yansıttığı düşünülen bu yanıtların kaynakları konusunda ise hâlâ çelişkiler bulunmaktadır. iUGP'de kullanılan "tone burst" uyaranın iniş/çıkış ve durasyon zamanları İşitsel Uyarılmış Beyinsapı Yanıtı (IUBC)'nda kullanılan "tone burst" uyarana göre daha uzun olduğundan IUGP'de frekansa spesifiklik artmakta ve spektral sıçramalar azalmaktadır. Ayrıca uyku ve bilinç durumundan etkilenmemesi, miyojenik aktiviteden daha az etkilenmesi gibi avantajları iUGP'yi diğer elektrofizyolojik test yöntemleri içinde ön plana çıkarmaktadır. Ancak IUGP kayıt tekniği ve kullanılan parametreler klinikten kliniğe farklılık gösterebilmektedir. Bu nedenle, her kliniğin kendine özel normatif verilerini oluşturması gerekmektedir.

Bu çalışmada, normal işitmeli ve sensorinoral işitme kayıplı kişilerde işitsel uyarılmış geç kortikal yanıtlar ve klasik davranışsal tekniklerle elde edilen işitme eşiği sonuçlarını karşılaştırarak kliniğimiz için tanısal değerlendirmede kullanılacak standart bir veri oluşturmak amaçlanmıştır.

\section{GEREÇ ve YÖNTEM}

Çalışmaya 18 normal işiten (33 kulak), 56 işitme kayıplı (110 kulak) olmak üzere toplam 74 (144 kulak) yetişkin alınmıştır. İşitme kayıplı grupta, kayıp dereceleri çok hafif ile çok ileri derece arasında değişmekle birlikte, 20 (40 kulak) kişide odyogram konfigürasyonu yüksek frekanslara doğru inen tipte, 36 (72 kulak) kişide düz tiptedir. Normal işiten grup 18-65 yaşları arasında olup, katılımcılar herhangi bir nörolojik, lisan ve konuşma sorunu olmayan yetişkinler arasından seçilmiştir. İşitme kayıplı grupta aynı şekilde 1865 yaşları arasında olup, sensörinöral işitme kayıplı yetişkinler arasından seçilmiştir. Nörolojik bozukluğu ve herhangi bir kulakta iletim patolojisi olanlar çalışmaya alınmamıştır. Tüm katılımcılara öncelikle akustik immitansmetri uygulanarak orta kulak sorunu ekarte edilmiş, sonrasında saf ses eşik odyometrisi ve konuşma odyometrisi uygulanarak işitme eşikleri belirlenmiştir.

Çalışma, Sağlık Bilimleri Enstitüsü Klinik Araştırmalar Ön Değerlendirme Komisyonu tarafından incelenip 30.03.2011 - 30 tarih ve sayısı ile etik kurul onayı alınarak yapılmıştır.

Rutin odyolojik incelemelerin ardından katılımcıların bir kısmında IUGP kaydı aynı gün içinde yapılırken, bir 
kısmında kooperasyonun bozukluğu ve zamanla ilgili kısıtlılıklar nedeni ile başka bir gün yapılmıştır. Odyolojik tetkikler ve iUGP kayıtları bu konuda tecrübeli farklı odyologlar tarafından yapılmıştır. IUGP kaydı öncesi katılımcıların elektrot yerleşim yerleri temizlenmiş, $\mathrm{Cz}$ noninverting elektrot (verteks), $\mathrm{A} 1$ inverting elektrot (ipsilateral kulak memesi) ve A2 toprak elektrot (kontralateral kulak memesi) olacak şekilde seçilerek yerleştirilmiştir.
Katılımcılar, International Acoustic Company standartlarına uygun olarak belirlenmiş sessiz odada, rahat bir koltukta oturarak test edilmiştir. Test sırasında katılımcılar tercihlerine göre film izlemiş ya da kitap okumuşlardır. Film izleyen katılımcılarda TV tam karşıda ve sesi kapalı olacak şekilde ayarlanmıştır.

Uyarılmış potansiyellerin kaydı için Biologic Navigator Pro 7. versiyon (Natus Medical; San Carlos, CA,

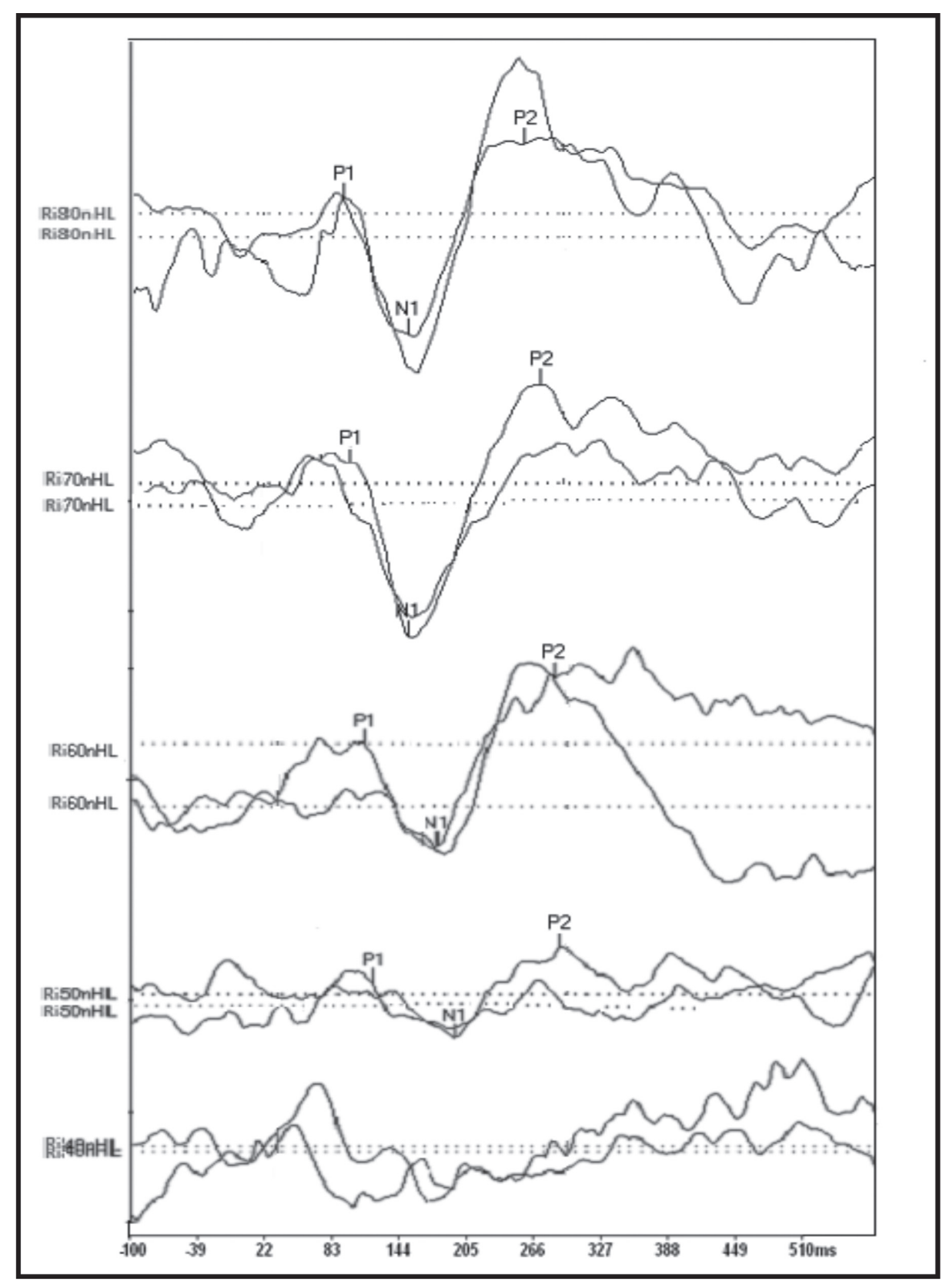

Figür 1. Normal işiten bir katılımcının sağ kulak 1000 Hz iUGP (P1-N1-P2) eşik incelemesi. 
USA) ve ICS Chartr EP (GN Otometrics/Natus Medical, Taastrup, Denmark) sistemleri kullanılmıştır. Her bir katılımcı için 500, 1000, 2000 ve 4000 Hz'lerdeki işitsel uyarılmış potansiyellerin P1-N1 ve P2 bileşenleri incelenmiştir (Örnek: Figür 1). Teste normal işitenlerde $30 \mathrm{~dB} \mathrm{nHL}$, işitme kayıplılarda $80 \mathrm{~dB} \mathrm{nHL}$ şiddet seviyesinden başlanıp, 10'ar dB'lik adımlarla inilerek/çıkılarak IUGP eşiği belirlenmiştir. Eşik seviyesinin belirlenmesinde 500 ve $1000 \mathrm{~Hz}$ için en düşük şiddet seviyesinde elde edilen N1-P2 dalga amplitüdü büyüklüğü $5 \mu V^{\prime}$ 'un üzerinde, 2000 ve $4000 \mathrm{~Hz}$ için 3 $\mu V^{\prime}$ 'un üzerinde ise eşik bu seviyenin $5 \mathrm{~dB}$ altı olarak kabul edilmiştir ${ }^{9}$. Her bir şiddet düzeyi için en az 2 kayıt yapılmıştır. Gerekli durumlarda özellikle eşik seviyesinde kayıtlar 3 ya da 4 kez yinelenmiştir. Test süresi, her bir katılımcı için elektrotların yapıştırılması ve uyarılmış yanıtların kaydı dâhil 45 dk. ile 1 saat arasında sürmüştür.

\section{Uyaran Tipi ve Özellikleri}

Uyaran tipi olarak 500, 1000, 2000 ve $4000 \mathrm{~Hz}$ tone burst kullanılmıştır. "Tone burst" uyaranın her bir frekans için seçilen çıkış/ plato/ iniş zamanları Tablo 1'de belirtilmiştir.

Tablo 1. Tone burst uyaran için kullanılan çıkış/ plato/ iniş zamanları.

\begin{tabular}{llll}
\hline Frekans & Çıkış Zamanı & Plato Zamanı & İniş Zamanı \\
\hline $500 \mathrm{~Hz}$ & $5 \mathrm{~ms}$. & $30 \mathrm{~ms}$. & $5 \mathrm{~ms}$. \\
$1000 \mathrm{~Hz}$ & $10 \mathrm{~ms}$. & $60 \mathrm{~ms}$. & $10 \mathrm{~ms}$. \\
$2000 \mathrm{~Hz}$ & $20 \mathrm{~ms}$. & $120 \mathrm{~ms}$. & $20 \mathrm{~ms}$. \\
$4000 \mathrm{~Hz}$ & $40 \mathrm{~ms}$. & $240 \mathrm{~ms}$. & $40 \mathrm{~ms}$. \\
& & & \\
\hline
\end{tabular}

Tablo 2. IUGP kayıt parametreleri.

\begin{tabular}{ll}
\hline Analiz zaman & $\begin{array}{l}\mathbf{- 1 0 0} \text { ms uyaran öncesi ve } \mathbf{5 0 0} \text { ms uyaran } \\
\text { sonrası }\end{array}$ \\
\hline Filtre & $1-30 \mathrm{~Hz}$ \\
Amplifikasyon & 50.000 \\
Kanal sayısı & Tek kanal \\
Polarite & Rarefaction \\
Averajlama sayısı & $20-50$ sweep \\
Uyaran tekrar sayısı & $0,7 / \mathrm{sn}$ \\
Artifact rejection & $+/-100 \mu \mathrm{V}$ \\
Elektrot yerleşimi & $\mathrm{Cz}, \mathrm{A} 1, \mathrm{~A} 2$ \\
& \\
\hline
\end{tabular}

\section{Uyarılmış Yanıtların Kaydı İçin Kullanılan Paramet- reler}

Kayıt sırasında kullanılan parametreler Tablo 2'de belirtilmiştir.

\section{İstatistiksel Yöntem}

Çalışmada elde edilen verilerin değerlendirilmesi ve tabloların oluşturulmasında SPSS (SPSS Inc, Chicago IL, USA) sürüm 23 kullanılmıştır. Grupların normal dağılım gösterip göstermediği Kolmogorov-Smirrnov SınamaSı ile incelenmiş, grupların normal dağılım gösterdiği saptanmıştır. Her iki gruptan elde edilen IUGP (P1N1-P2) ve davranışsal saf ses işitme eşikleri ortalama ve standart sapma değerleri için tanımlayıcı istatistik kullanılmıştır. Normal ve işitme kayıplı gruplarda ölçümle elde edilen değerler arasındaki farkın anlamlıIığı için Eşleştirilmiş Örneklem T-Testi, arasındaki ilişki için ise Pearson Korelasyon Testi kullanılmıştır. İşitme kayıplı grupta düz ve dik eğimli olmak üzere odyogram konfügürasyonu bakımından yapılan ayrımda her iki işitme kayıplı gruptan elde edilen IUGP ve davranım eşiği ortalama farklarının (iUGP ortalaması-Davranım Odyometrisi ortalaması) birbirleri ile olan farklarını incelemek için Bağımsız Örneklem T-Testi kullanılmıştır. Bütün istatistiksel analizlerde anlamlılık düzeyi olarak $p<0,05$ değeri kabul edilmiştir.

\section{BULGULAR}

Pearson Korelasyon analizine göre, normal işitenlerde IUGP ve davranım eşikleri arasında her iki kulakta $500 \mathrm{~Hz}$ 'de anlamlı bir korelasyon olmadığı, 1000 Hz'de sağ kulakta güçlü, sol kulakta orta derecede bir korelasyon olduğu, 2000 Hz'de sağ kulakta anlamlı bir korelasyon olmadığı, sol kulakta orta derecede bir korelasyon olduğu, $4000 \mathrm{~Hz}$ 'de ise sağ kulakta zayıf bir korelasyon olduğu, sol kulakta anlamlı bir korelasyon olmadığı görülmüştür (Tablo 3). Her iki test arasındaki ortalama farklar incelendiğinde, en fazla farkın sağ kulakta $4.1 \mathrm{~dB}$, sol kulakta $5 \mathrm{~dB}$ olduğu ve 4000 Hz'de elde edildiği görülmüştür. Ortalama farklar bakımından diğer frekanslardaki sıralama büyükten küçüğe doğru sağ kulakta 2000, 500 ve 1000 Hz, 
sol kulakta 2000, 1000 ve $500 \mathrm{~Hz}$ şeklindedir. Her iki kulakta da 500 ve $1000 \mathrm{~Hz}$ frekanslarında elde edilen ortalama farklar istatiksel açıdan anlamlı değilken, 2000 ve $4000 \mathrm{~Hz}$ frekanslarındaki ortalama farklar istatiksel açıdan anlamlıdır (Tablo 4).

Tablo 3. Normal işiten grubun sağ ve sol kulak iUGP ve davranım eşikleri arasındaki korelasyon.

\begin{tabular}{lllll}
\hline Sağ Kulak & N & Korelasyon (r) & p \\
\hline $500 \mathrm{~Hz}$ & IUGP & 18 & 0.914 & 0.176 \\
& Odyometri & 18 & & \\
$1000 \mathrm{~Hz}$ & iUGP & 18 & 0.937 & $0.001^{*}$ \\
& Odyometri & 18 & & \\
$2000 \mathrm{~Hz}$ & iUGP & 18 & 0.955 & 0.160 \\
& Odyometri & 18 & & \\
$4000 \mathrm{~Hz}$ & iUGP & 18 & 0.890 & $0.050^{*}$ \\
& Odyometri & 18 & & \\
\hline \multirow{2}{*}{ Sol Kulak } & & $\mathbf{N}$ & Korelasyon (r) & $\mathbf{p}$ \\
\hline \multirow{2}{*}{$500 \mathrm{~Hz}$} & iUGP & 15 & 0.909 & 0.136 \\
& Odyometri & 15 & & $0.015^{*}$ \\
$1000 \mathrm{~Hz}$ & iUGP & 15 & 0.940 & $0.021^{*}$ \\
& Odyometri & 15 & & 0.208 \\
$2000 \mathrm{~Hz}$ & iUGP & 15 & 0.914 & \\
& Odyometri & 15 & &
\end{tabular}

*: p<0,05, N: Örneklem büyüklüğü
İşitme kayıplı grupta; her iki kulakta tüm frekanslarda IUGP ve davranım eşikleri arasında yüksek bir korelasyon olduğu görülmüştür. IUGP ve davranım eşikleri arasında en yüksek korelasyon sağ kulakta 2000 Hz'de, sol kulakta 1000 Hz'de elde edilmiştir (Tablo 5). Her iki test arasındaki en büyük ortalama fark sağ kulakta $7.4 \mathrm{~dB}$, sol kulakta $7.2 \mathrm{~dB}$ olup, sağ kulakta

Tablo 5. İşitme kayıplı grubun sağ ve sol kulak iUGP ve davranım eşikleri arasındaki korelasyon.

\begin{tabular}{lllll}
\hline Sağ Kulak & N & Korelasyon (r) & p \\
\hline $500 \mathrm{~Hz}$ & iUGP & 56 & 0.914 & $0.000^{*}$ \\
& Odyometri & 56 & & \\
$1000 \mathrm{~Hz}$ & iUGP & 56 & 0.937 & $0.000^{*}$ \\
& Odyometri & 56 & & $0.000^{*}$ \\
$2000 \mathrm{~Hz}$ & iUGP & 56 & 0.955 & \\
& Odyometri & 56 & & $0.000^{*}$ \\
$4000 \mathrm{~Hz}$ & iUGP & 56 & 0.890 & \\
& Odyometri & 56 & & $\mathbf{p}$ \\
\hline \multirow{2}{*}{ Sol Kulak } & & $\mathbf{N}$ & Korelasyon (r) & $0.000^{*}$ \\
& & & \\
$500 \mathrm{~Hz}$ & iUGP & 54 & 0.909 & $0.000^{*}$ \\
& Odyometri & 54 & & $0.000^{*}$ \\
$1000 \mathrm{~Hz}$ & iUGP & 54 & 0.940 & $0.000^{*}$ \\
& Odyometri & 54 & & \\
$2000 \mathrm{~Hz}$ & iUGP & 54 & 0.914 & \\
& Odyometri & 54 & & \\
$4000 \mathrm{~Hz}$ & iUGP & 54 & 0.914 & \\
& Odyometri & 54 & &
\end{tabular}

*: p<0,05, N: Örneklem büyüklüğü

Tablo 4. Normal işiten grubun sağ ve sol kulak IUGP ve davranım eşik ortalamaları farkı.

\begin{tabular}{|c|c|c|c|c|c|c|}
\hline \multicolumn{2}{|l|}{ Sağ Kulak } & \multirow{2}{*}{$\frac{\mathbf{N}}{18}$} & \multirow{2}{*}{$\begin{array}{l}\text { Ortalama (dB) } \\
8.0\end{array}$} & \multirow{2}{*}{$\begin{array}{l}\text { Std. Sapma } \\
5.97\end{array}$} & \multirow{2}{*}{$\begin{array}{l}\text { Ortalama fark (dB) } \\
1.9\end{array}$} & \multirow{2}{*}{$\frac{p}{0.261}$} \\
\hline $500 \mathrm{~Hz}$ & IUGP & & & & & \\
\hline & Odyometri & 18 & 6.1 & 6.31 & & \\
\hline \multirow[t]{2}{*}{$1000 \mathrm{~Hz}$} & IUGP & 18 & 7.2 & 8.26 & 1.3 & 0.331 \\
\hline & Odyometri & 18 & 5.8 & 4.61 & & \\
\hline \multirow[t]{2}{*}{$2000 \mathrm{~Hz}$} & IUGP & 18 & 8.6 & 6.59 & 3.3 & $0.048^{*}$ \\
\hline & Odyometri & 18 & 5.2 & 4.68 & & \\
\hline \multirow[t]{2}{*}{$4000 \mathrm{~Hz}$} & IUGP & 18 & 10.0 & 6.41 & 4.1 & $0.017^{*}$ \\
\hline & Odyometri & 18 & 5.8 & 6.47 & & \\
\hline \multicolumn{2}{|l|}{ Sol Kulak } & $\mathbf{N}$ & Ortalama (dB) & Std. Sapma & Ortalama fark (dB) & $\mathbf{p}$ \\
\hline \multirow[t]{2}{*}{$500 \mathrm{~Hz}$} & IUGP & 15 & 6.6 & 3.61 & 0.3 & 0.843 \\
\hline & Odyometri & 15 & 6.3 & 6.93 & & \\
\hline \multirow[t]{2}{*}{$1000 \mathrm{~Hz}$} & IUGP & 15 & 7.3 & 7.03 & 1.6 & 0.313 \\
\hline & Odyometri & 15 & 5.6 & 7.03 & & \\
\hline \multirow[t]{2}{*}{$2000 \mathrm{~Hz}$} & IUGP & 15 & 9.3 & 7.28 & 4.3 & $0.013^{*}$ \\
\hline & Odyometri & 15 & 5.0 & 6.47 & & \\
\hline \multirow[t]{2}{*}{$4000 \mathrm{~Hz}$} & IUGP & 15 & 9.0 & 8.49 & 5.0 & $0.038 *$ \\
\hline & Odyometri & 15 & 4.0 & 5.68 & & \\
\hline
\end{tabular}

*: $p<0,05, N$ : Örneklem büyüklüğü 
$2000 \mathrm{~Hz}$, sol kulakta $500 \mathrm{~Hz}$ frekansında elde edilmiştir. Sağ kulakta 500 ve 1000 Hz'de elde edilen ortalama fark eşit olup, en az fark elde edilen frekans $4000 \mathrm{~Hz}$ 'tir. Sol kulakta ise ortalama fark bakımından büyükten küçüğe doğru sıralama 500, 1000, 4000 ve $2000 \mathrm{~Hz}$ şeklindedir. IUGP ve davranım eşiği arasındaki ortalama fark değerleri tüm frekanslarda negatif yönde olup, istatiksel açıdan anlamlıdır (Tablo 6).

Düz ve yüksek frekanslara doğru dik eğimli olmak üzere iki farklı odyogram konfigürasyonuna sahip işitme kayıplı grubun IUGP ve davranım eşiği ortalamaları arasındaki fark değerleri karşılaştırıldığında, her iki işitme kayıplı grup arasında IUGP ve davranım eşiği bakımından yalnızca 1000 Hz'de anlamlı bir fark olduğu diğer frekanslarda anlamlı bir fark olmadığı görülmüştür (Tablo 7).

Grup içinde elde edilen her iki test sonuçlarının birbiri ile hangi oranda uyumluluk gösterdiği incelendiğinde, normal grupta 500, 1000, 2000 ve 4000 Hz'de test edilen kulakların sırasıyla \%93,3, \%96,3, \%90,9 ve $\% 87,8$ 'inin, işitme kayıplı grupta $\% 67,2, \% 71,8$, $\% 71,8$ ve $\% 73,6$ 'sının $\pm 10 \mathrm{~dB}$ içinde birbiri ile uyumlu olduğu görülmüştür. Her iki test sonucu arasında elde edilen en büyük fark değeri 35 dB olup, işitme kayıplı

Tablo 6. İşitme kayıplı grubun sağ ve sol kulak IUGP ve davranım eşik ortalamaları farkı.

\begin{tabular}{|c|c|c|c|c|c|c|}
\hline \multicolumn{2}{|l|}{ Sağ Kulak } & \multirow{2}{*}{$\frac{N}{56}$} & \multirow{2}{*}{$\begin{array}{l}\text { Ortalama (dB) } \\
39.3\end{array}$} & \multirow{2}{*}{$\begin{array}{l}\text { Std. Sapma } \\
23.08\end{array}$} & \multirow{2}{*}{$\begin{array}{l}\text { Ortalama fark (dB) } \\
-6.9\end{array}$} & \multirow{2}{*}{$\frac{\mathbf{p}}{0.000^{*}}$} \\
\hline $500 \mathrm{~Hz}$ & IUGP & & & & & \\
\hline & Odyometri & 56 & 46.3 & 22.95 & & \\
\hline \multirow[t]{2}{*}{$1000 \mathrm{~Hz}$} & IUGP & 56 & 47.3 & 24.82 & -6.9 & $0.000^{*}$ \\
\hline & Odyometri & 56 & 54.2 & 25.50 & & \\
\hline \multirow[t]{2}{*}{$2000 \mathrm{~Hz}$} & IUGP & 56 & 53.6 & 24.73 & -7.4 & $0.000 *$ \\
\hline & Odyometri & 56 & 61.2 & 25.53 & & \\
\hline \multirow[t]{2}{*}{$4000 \mathrm{~Hz}$} & IUGP & 56 & 62.5 & 22.13 & -6.3 & $0.000 *$ \\
\hline & Odyometri & 56 & 68.8 & 22.40 & & \\
\hline \multicolumn{2}{|l|}{ Sol Kulak } & $\mathbf{N}$ & Ortalama (dB) & Std. Sapma & Ortalama fark (dB) & $\mathbf{p}$ \\
\hline \multirow[t]{2}{*}{$500 \mathrm{~Hz}$} & IUGP & 54 & 35.7 & 21.78 & -7.2 & $0.000^{*}$ \\
\hline & Odyometri & 54 & 43.0 & 23.91 & & \\
\hline \multirow[t]{2}{*}{$1000 \mathrm{~Hz}$} & IUGP & 54 & 44.4 & 25.21 & -7.0 & $0.000^{*}$ \\
\hline & Odyometri & 54 & 51.5 & 26.36 & & \\
\hline \multirow[t]{2}{*}{$2000 \mathrm{~Hz}$} & IUGP & 54 & 52.7 & 23.66 & -4.4 & $0.000 *$ \\
\hline & Odyometri & 54 & 57.1 & 25.76 & & \\
\hline \multirow[t]{2}{*}{$4000 \mathrm{~Hz}$} & IUGP & 54 & 59.5 & 22.81 & -5.2 & $0.000^{*}$ \\
\hline & Odyometri & 54 & 64.8 & 25.58 & & \\
\hline
\end{tabular}

*: p<0,05, N: Örneklem büyüklüğü

Tablo 7. İşitme kayıplı grupta IUGP ve davranım eşikleri arasındaki ortalama fark değerlerinin frekans ve odyogram konfigürasyonuna göre dağılımları.

\begin{tabular}{|c|c|c|c|c|c|}
\hline Frekans & Konfigürasyon & $\mathbf{N}$ & Ortalama fark (dB) & Std. Sapma & $\mathbf{p}$ \\
\hline \multirow[t]{2}{*}{$500 \mathrm{~Hz}$} & Düz & 40 & 0,2817 & 23.7980 & 0.557 \\
\hline & Eğimli & 72 & 0.8750 & 8.6519 & \\
\hline \multirow[t]{2}{*}{$1000 \mathrm{~Hz}$} & Düz & 40 & -1.5493 & 13.9281 & $0.018^{*}$ \\
\hline & Eğimli & 72 & -6.000 & 6.9981 & \\
\hline \multirow[t]{2}{*}{$2000 \mathrm{~Hz}$} & Düz & 40 & -5.7746 & 12.8075 & 0.936 \\
\hline & Eğimli & 72 & -4.7500 & 8.2392 & \\
\hline \multirow[t]{2}{*}{$4000 \mathrm{~Hz}$} & Düz & 40 & -5.3750 & 12.8075 & 0.946 \\
\hline & Eğimli & 72 & -5.7746 & 8.6519 & \\
\hline
\end{tabular}

*: $p<0,05$, : Örneklem büyüklüğü 
Tablo 8. Normal işitmeli grupta iUGP ve davranım eşikleri arasındaki ortalama fark değerlerinin yüzde olarak dağılımları.

\begin{tabular}{lllll}
\hline Frekans & Birebir eşleşme & $\mathbf{5 ~ d B}$ içinde & $\mathbf{1 0} \mathbf{d B}$ içinde & $\mathbf{1 5} \mathbf{d B}$ ve üzerinde \\
\hline $500 \mathrm{~Hz}$ & $\% 33.3(11)$ & $\% 78.7(26)$ & $\% 93.9(31)$ & $\% 6.0(2)$ \\
$1000 \mathrm{~Hz}$ & $\% 24.2(8)$ & $\% 81.8(27)$ & $\% 96.9(32)$ & $\% 3.0(1)$ \\
$2000 \mathrm{~Hz}$ & $\% 18.1(6)$ & $\% 72.7(24)$ & $\% 90.9(30)$ & $\% 9.0(3)$ \\
$4000 \mathrm{~Hz}$ & $\% 24.2(8)$ & $\% 63.6(21)$ & $\% 87.8(29)$ & $\% 12.1(4)$ \\
\hline
\end{tabular}

Kulak sayıları parantez içinde belirtilmiştir.

Tablo 9. İşitme kayıplı grupta IUGP ve davranım eşikleri arasındaki fark değerlerinin yüzde olarak dağıımları.

\begin{tabular}{lllll}
\hline Frekans & Birebir eşleşme & $\mathbf{5 ~ d B}$ içinde & 10 dB içinde & 15 dB ve üzerinde \\
\hline $500 \mathrm{~Hz}$ & $\% 17.2(19)$ & $\% 40.9(45)$ & $\% 67.2(74)$ & $\% 32.7(36)$ \\
$1000 \mathrm{~Hz}$ & $\% 17.2(19)$ & $\% 47.2(52)$ & $\% 71.8(79)$ & $\% 28.1(31)$ \\
$2000 \mathrm{~Hz}$ & $\% 16.3(18)$ & $\% 46.3(51)$ & $\% 71.8(79)$ & $\% 28.1(31)$ \\
$4000 \mathrm{~Hz}$ & $\% 9.0(12)$ & $\% 45.4(50)$ & $\% 73.6(81)$ & $\% 26.3(29)$ \\
\hline
\end{tabular}

Kulak sayıları parantez içinde belirtilmiştir.

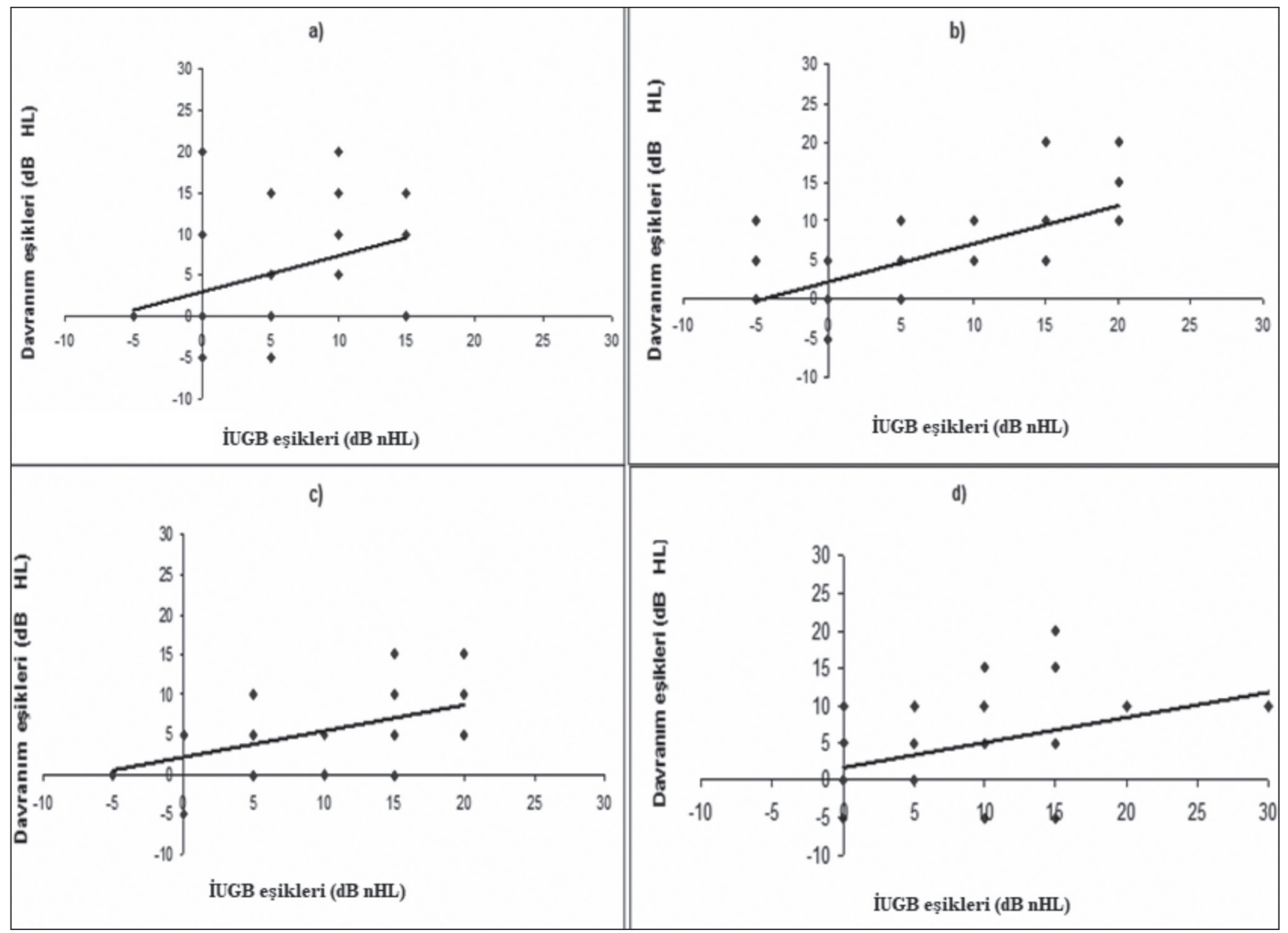

Figür 2. Normal işiten grupta iUGP ve davranım eşiklerinin karşılaştırılması a) $500 \mathrm{~Hz}$ b) $1000 \mathrm{~Hz}$ c) $2000 \mathrm{~Hz}$ d) $4000 \mathrm{~Hz}$ (Her bir nokta birden fazla kulak sayısını gösterebilmektedir). 


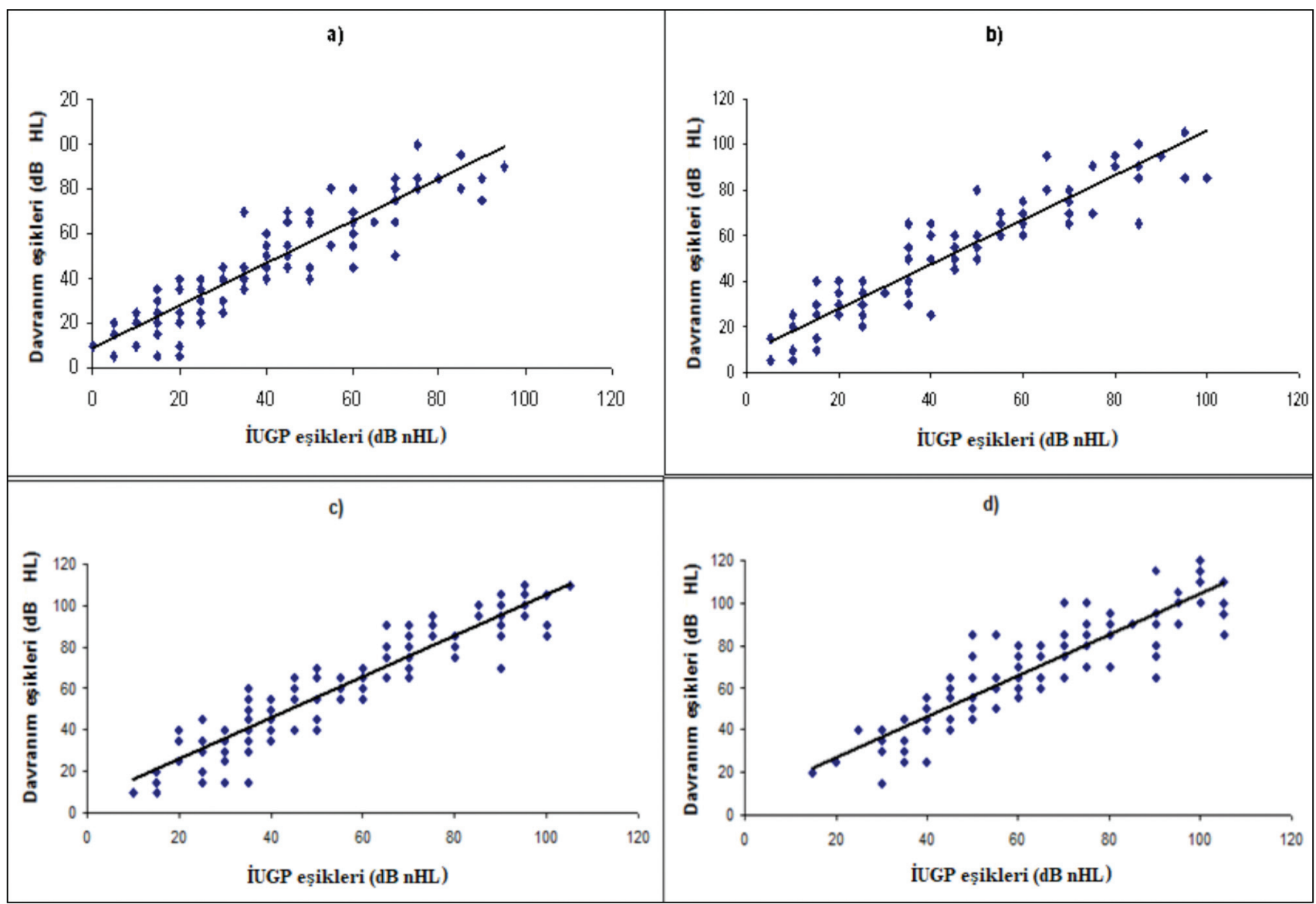

Figür 3. İşitme kayıplı grupta IUGP ve davranım eşiklerinin karşılaştırılması a) 500 Hz b) $1000 \mathrm{~Hz}$ c) $2000 \mathrm{~Hz}$ d) $4000 \mathrm{~Hz}(\mathrm{Her}$ bir nokta birden fazla kulak sayısını gösterebilmektedir).

grupta elde edilmiştir. Elde edilen diğer fark değerlerinin frekanslar üzerinde yüzde olarak dağılımları Tablo 8 ve Tablo 9'da gösterilmektedir. IUGP ve davranım eşiği karşılaştırılmaları ise Figür 2 ve Figür 3 'te gösterilmektedir.

\section{TARTIŞMA ve SONUÇ}

Normal işiten ve sensörinöral işitme kayıplı kişilerden oluşan iki grup arasındaki IUGP ve davranım odyometrisi sonuçlarının karşılaştırıldığı bu çalışmada, her iki test ile elde edilen sonuçlar arasında anlamlı bir farklılık olmadığı, sonuçların büyük oranda $\pm 10 \mathrm{~dB}$ içinde uyumluluk gösterdiği sonucuna varılmıştır.

Çalışmamızda, iUGP'nin frekansa özgü eşik belirlemedeki yerini değerlendirmek üzere her bir frekansta elde edilen IUGP ve davranım eşikleri karşılaştırılmış ve aralarındaki korelasyon değerleri hesaplanmıştır. Benzer şekilde Tomlin ve ark. ve Biago'nun İşitsel Devamlı Durum Yanıtları (IDDC), IUGP ve davranım eşiklerini karşılaştırdıkları çalışmalarında, her iki testin de davranım eşikleri ile yüksek korelasyon gösterdiğini, IUGP'nin iDDC'ye göre davranım eşiklerine daha yakın sonuçlar verdiğini görmüşlerdir. Tomlin ve ark.'nın ${ }^{11}$ çalışmasında, IUGP eşikleri ile davranım eşikleri arasında en yüksek korelasyon 500 ve $4000 \mathrm{~Hz}$ frekanslarında elde edilirken, Biago'nun çalışmasında, en yüksek korelasyon 2000 ve $4000 \mathrm{~Hz}$ frekanslarında elde edilmiş ve tipik olarak yüksek frekans işitme kaybı görülen mesleki gürültüye bağlı işitme kayıplarının belirlenmesinde IUGP'nin güvenilir bir test olduğu ileri sürülmüştür ${ }^{6}$. Çalışmamızda ise, karşılaştırılan frekanslarda hem işitme kayıplı hem de 
normal işiten grup içinde en yüksek korelasyon 1000 ve $2000 \mathrm{~Hz}$ frekanslarında elde edilmiştir.

Literatürde IUGP eşikleri ile davranım eşiklerinin karşılaştırıldığı birçok çalışma bulunmaktadır. Örneğin, Betty ve ark.'nın ${ }^{12} 2002$ yılında nonorganik işitme kayıplarının tespitinde IUGP'nin ne kadar güvenilir bir yöntem olduğunu incelemek üzere yaptıkları çaIışmalarında, IUGP eşikleri ile davranım eşikleri karşılaştırılmıştır. İki yüz dört kişinin katılımı ile gerçekleştirilen bu çalışmada, 1000, 2000 ve 3000 Hz'de test edilen kulakların sırasıyla \%25,1, \%28,7, \%4,9'unda IUGP ve davranım eşikleri arasında birebir eşleşme olduğu, \%85,9, \%86,9, \%83,2'sinde iUGP ve davranım eşiklerinin $10 \mathrm{~dB}$ içinde uyumlu olduğu görülmüştür. Çalışmamızda da benzer şekilde 500, 1000, 2000 ve $4000 \mathrm{~Hz}$ 'de olmak üzere IUGP ve davranım eşikleri karşılaştırılmış, sırasıyla test edilen kulakların \%67,2, $\% 71,8, \% 71,8$ ve $\% 73,6$ 'sında IUGP ve davranım eşiklerinin $\pm 10 \mathrm{~dB}$ içinde uyumlu olduğu belirlenmiştir. Frekanslar arasında istatistiksel olarak anlamlı bir fark olmamakla birlikte, en düşük uyumluluk oranın $500 \mathrm{~Hz}$ 'de olduğu ve her iki test eşiği arasında elde edilen en fazla farkın 35 dB olduğu görülmüştür.

iUGP'de kullanılan "tone burst" uyaranın çıkış, iniş ve durasyon zamanlarının erken latanslara göre daha uzun oluşu "tone burst" uyaranın spektral sıçramalarını azaltmakta, böylece daha frekansa özgü yanıtlar elde edilmesini sağlamaktadır ${ }^{13}$. Çalışmamızda da özellikle işitme kayıplılarda test edilen tüm frekanslarda davranım eşikleri ile IUGP eşiklerinin güçlü bir korelasyon göstermesi, IUGP'nin frekansa özgü bilgi sağlamadaki üstünlüğünü destekler nitelikte olmuştur.

IUGP ve davranım eşikleri arasında elde edilen korelasyon değerlerinin normal ve işitme kayıplılarda nasıl değiştiğini incelendiğimizde ise işitme kayıplılarda normallere göre daha güçlü bir korelasyon olduğu görülmüştür. Yapılan çalışmalarda, benzer bulguların diğer elektrofizyolojik test yöntemleri için de geçerli olduğu ve ancak diğer test yöntemlerine kıyasla iUGP'nin normal işitenlerde davranım eşikleri ile daha yüksek korelasyon gösterdiği ileri sürülmektedir ${ }^{6,7}$.
Yeung ve ark.'nın ${ }^{14}$ eşik belirlemedeki üstünlükleri bakımından IUGP ve IDDC ölçümlerini karşılaştırdıkları çalışmalarında, her iki testin de işitme kayıplılarda normallere göre daha yüksek doğrulukta sonuçlar verdiği ve işitme kaybının derecesinin artmasıyla elde edilen sonuçların doğruluğunun da arttığı ileri sürülmüştür. Literatürde benzer bulguların elde edildiği çalışmalarda, bu durumun rekruitmentla ilişkili olduğu, işitme kayıplılarda şiddetin artması ile meydana gelen fizyolojik yanıtın amplitüdünün de artış gösterdiği ileri sürülmektedir ${ }^{6,9}$. Çalışmamızda, amplitüdler değerlendirilmemekle birlikte, eşik incelemesi sırasında benzer etkinin görüldüğü gözlenmiştir.

Çalışmamızda, normal işitenlerde iUGP ile davranım eşikleri arasında $500 \mathrm{~Hz}$ 'de anlamlı bir korelasyon olmadığı, 1000 Hz'de sağ kulakta güçlü, sol kulakta orta derecede bir korelasyon olduğu, 2000 Hz'de sağ kulakta anlamlı bir korelasyon olmadığı, sol kulakta orta derecede bir korelasyon olduğu, $4000 \mathrm{~Hz}$ 'de ise sağ kulakta zayıf bir korelasyon olduğu, sol kulakta anlamlı bir korelasyon olmadığı görülmüştür. Korelasyon değerleri yüksek olmamasına karşın, eşikler arasındaki farkın en fazla $20 \mathrm{~dB}$ olduğu ve hemen her vakada, IUGP eşiklerinin normal işitme sınırlarında kaldığı görülmüştür. Bu durumda normal işitenlerde iUGP'nin genel olarak işitme seviyesi ile ilgili doğru bilgi verebileceğini söylemek olasıdır.

Klinikte objektif testlerin uygulanmasını gerektiren vakaların başında davranım testlerine kooperasyon kuramayan ya da nonorganik işitme kaybı şüphesi taşıyan kişilerin geldiği görülmektedir. Bu gibi vakalarda otoakustik emisyon ve akustik immitansmetri gibi kısa ve pratik test yöntemleri ile normal işitme, işitme kaybından kolay bir şekilde ayrılabilmekte ancak işitme kaybının olduğu durumlarda kaybın miktar ve derecesi belirlenememektedir. Bu nedenle IUGP'nin normal işitenlerde davranım eşikleri ile zayıf korelasyon göstermesinin, nonorganik komponentini açığa çıkarmada önemli bir sınırlılık yaratmadığı, tam tersi işitme kayıplılarda davranım eşikleriyle yüksek korelasyon göstermesi bakımından işitme kayıplarının belirlenmesinde önemli bir yere sahip olduğu söylenebilir. 
Normal ve işitme kayıplı grup IUGP ve davranım eşikleri arasındaki ortalama farklar bakımından karşılaştırıldığında ise normal işitenlerden elde edilen ortalama farkların pozitif yönlü, işitme kayıplılardan elde edilen ortalama farkların ise negatif yönlü olduğu görülmüştür. Bu durum normal grupta IUGP eşiklerinin davranım eşiklerine göre daha kötü olduğunu, işitme kayıplı grupta ise daha iyi olduğunu göstermektedir. Normal işitenlerde eşik tespit edilirken eşik seviyesine doğru inildikçe akustik uyaranın ilişkisiz EEG (elektroensefalografi) gürültüsünden ayrıştırılması zorlaştığından dalga morfolojisi bozulmakta, bu durum eşik belirlenmesini zorlaştırmaktadır ${ }^{15,16}$. Normal işiten grupta IUGP eşiklerinin davranım eşiklerine göre daha kötü olmasının nedenini bununla açıklamak olasıdır. Buna karşın Betty ve ark.'nın ${ }^{12}$ yaptığı çalışmada, hem normal hem de işitme kayıplı gruptan elde edilen IUGP eşik ortalamalarının saf ses eşik ortalamalarından kötü elde edildiği, bunun nedeni olarak da elektriksel yanıtları elde edebilmek için eşik üstü bir uyaran gerektiği ileri sürülmüştür.

iUGP ile eşik belirlenmesini zorlaştıran en önemli faktörlerin başında kişilerin dikkat ve uyanıklık durumları gelmektedir. IUGP ile her bir frekansta eşik belirlemek oldukça uzun sürdüğünden kişilerin dikkat ve bilinç durumları test süresince değişmektedir. Böyle bir durumda klinisyen test etmekte olduğu kişinin dikkatini uyanık tutmak için uygun yöntemi seçmek zorundadır. Çalışmamızda buna dikkat edilmiş, test sırasında katılımcılardan yeğlemelerine göre kitap okumaları ya da film izlemeleri istenerek bu durum kontrol edilmeye çalışıımıştır. Uyuklama ya da sıkılma belirtileri gözlendiği durumlarda teste ara verilerek katılımcıların yine uyanık olmaları sağlandıktan sonra teste devam edilmiştir. Bu durumda her bir frekansta eşik belirlerken iUGP'nin kısa süren bir test olmadığını ve bunun bir dezavantaj oluşturduğunu söylemek olasıdır. Literatürde eşik belirlemede kullanılan elektrofizyolojik test yöntemlerini süreleri bakımından karşılaştıran bazı çalışmalarda iUGP'nin diğer yöntemlere göre avantajlı olduğu ileri sürülmüştür ${ }^{15,17}$. Buna karşın Yeung ve ark.'nın ${ }^{14}$ yaptığı çalışmada, IUGP ile eşik belirlemenin IDDC'ye kıyasla daha çok zaman aldığı ileri sürülmüştür.
Elektrofizyolojik ölçümler sırasında en sık karşılaşılan ve eşik belirlemeyi önemli ölçüde zorlaştıran sorunlardan biri de kas ve harekete bağlı oluşan artifaklardır. Özellikle nonorganik işitme kayıplarında vakalar uyumaya direnç gösterme ya da bilinçli olarak hareket edip artifakta neden olma eğiliminde olduklarından IUBC gibi sedasyon gerektiren yöntemlerle test edilmeleri güç olmaktadır. Bu durumda IUGP, diğer elektrofizyolojik test yöntemlerine göre miyojenik gürültüden daha az etkilenmesi bakımından avantajlı olup, nonorganik işitme kayıplarında kritik bir önem taşımaktadır.

Testler farklı günlerde yapılabildiğinden, iletim tipi işitme kayıplarının doğası gereği oluşabilecek odyometrik eşik farklılıklarının, sonuçları etkilemesinden kaçınmak üzere çalışmamızda işitme kayıplı grup, sadece sensorinöral işitme kayıplı kişilerden oluşturulmuştur. Literatürde de IUGP ile ilgili yapılan çalışmalarda sıklıkla sensörinöral işitme kayıplı kişiler yeğlenmiştir ${ }^{1,6,7,14}$.

Tüm avantajları gözden geçirildiğinde, frekansa özgü eşik bilgisi sağlaması, miyojenik gürültüden daha az etkilenmesi, sedasyon gerektirmemesi ve noninvaziv olarak uygulanan bir test olması bakımından iUGP'nin nonorganik işitme kayıplarında kullanılabilecek uygun bir objektif test yöntemi olduğu söylenebilir.

\section{SONUÇ}

Sonuç olarak, IUGP'nin iç kulaktan kortekse kadar olan nöral yollar boyunca işitme sistemini değerlendirmeye olanak sağlayan, eşik belirlemede doğru ve güvenilir sonuçlar veren objektif bir test yöntemi olduğu söylenebilir. Bu bakımından IUGP, davranım odyometrisini gerçekleştiremeyen küçük çocuk ve yetişkinlerde, ayrıca objektif işitme ölçümüne gerek duyulan nonorganik işitme kayıplı kişilerde ve medikolegal vakalarda kullanılabilecek uygun bir test yöntemi olarak önerebilir. 


\section{KAYNAKLAR}

1. Stach B. Clinical audiology: An introduction: Nelson Education 2008.

2. Lin J, Staecker H. Nonorganic hearing loss. Seminars in neurology: Thieme Medical Publishers, Inc., 333 Seventh Avenue, New York, USA. 2006:321-30.

3. Hall JW. Handbook of Auditory Evoked Responses: Allyn and Bacon 1992.

4. Martin FN, Clark JG. Introduction to audiology: Allyn and Bacon Boston 1997.

5. Stephen WH, Garry N, Ivan K, et al. The use of cortical evoked response audiometry in the assessment of noise-induced hearing loss. Otolaryngology Head and Neck Surgery. 2003;128(2):257-62.

https://doi.org/10.1067/mhn.2003.79

6. Biagio L. Slow cortical auditory evoked potentials and auditory steady-state evoked responses in adults exposed to occupational noise. University of Pretoria 2009.

7. Biagio L, Swanepoel DW, Soer ME. Objective assessment of noise-induced hearing loss: a comparison of methods. 2009.

8. Alberti P, Hyde M, Riko K. Exaggerated hearing loss in compensation claimants. The Journal of otolaryngology. 1987;16(6):362-6.

9. Lightfoot G, Kennedy V. Cortical electric response audiometry hearing threshold estimation: accuracy, speed, and the effects of stimulus presentation features. Ear and hearing. 2006;27(5):443-56. https://doi.org/10.1097/01.aud.0000233902.53432.48

10. Boniver R. Slow auditory evoked potentials: the end of malingering in audiology. International Tinnitus Journal. 2002;8(1):58-61.

11. Tomlin D, Rance G, Graydon K, et al. A comparison of 40 $\mathrm{Hz}$ auditory steady-state response (ASSR) and cortical au- ditory evoked potential (CAEP) thresholds in awake adult subjects: Comparación de umbrales con $40 \mathrm{~Hz}$ ASSR y CAEP en adultos despiertos. International Journal of Audiology. 2006;45(10):580-8.

https://doi.org/10.1080/14992020600895170

12. Tsui B, Wong LL, Wong EC. Accuracy of cortical evoked response audiometry in the identification of non-organic hearing loss: International Journal of Audiology. 2002;41(6):330-3. https://doi.org/10.3109/14992020209090407

13. Hall III J. eHandbook of auditory evoked responses: Principles, procedures \& protocols. Kindle Direct Publishing 2015.

14. Yeung KN, Wong LL. Prediction of hearing thresholds: Comparison of cortical evoked response audiometry and auditory steady state response audiometry techniques: Predicción de umbrales auditivos. Comparación entre las técnicas de Audiometría por Respuestas Evocadas Corticales y Audiometría por Respuestas Auditivas de Estado Estable. International Journal of Audiology. 2007;46(1):17-25. https://doi.org/10.1080/14992020601102238

15. Van Maanen A, Stapells DR. Comparison of multiple Auditory Steady-State Responses ( 80 versus $40 \mathrm{~Hz}$ ) and slow cortical potentials for threshold estimation in hearing-impaired adults: Comparación de las respuestas auditivas múltiples de estado estable ( 80 vs $40 \mathrm{~Hz}$ ) y de los potenciales corticales lentos en la estimación de umbrales en adultos con hipoacusia. International Journal of Audiology. 2005;44(11):613-24. https://doi.org/10.1080/14992020500258628

16. Stapells DR. Cortical event-related potentials to auditory stimuli. Handbook of Clinical Audiology. 2002;5:378-406.

17. Dejonckere PH, Coryn CP. A Comparison Between Middle Latency Responses and Late Auditory Evoked Potentials for Approximating Frequency-Specific Hearing Levels in Medicolegal Patients with Occupational Hearing Loss. International Tinnitus Journal. 2000;6(2):175-81. 